\title{
Human Capital and Economic Growth: An empirical investigation using panel data
}

\author{
Miethy Zaman \\ (MSc Student, Economics, University of Nottingham, United Kingdom)
}

\begin{abstract}
This paper investigates the effect of human capital on economic growth. Under a hybrid specification, for a sample of 100 countries, using panel data for the period 1980-2005, the empirical outputs provide considerable evidence for a dual role of human capital in determining economic growth. The sensitivity of the findings is evaluated by subjecting the estimations to different sub-samples. Some specific problems relating to the measures of human capital and technology gap are also outlined. Future research should focus on building more refine hybrid models and constructing more comprehensive measures of human capital.
\end{abstract}

Keywords: capital, dual, growth, hybrid, panel.

\section{Introduction}

Human capital has been considered as an important determinant of economic growth both theoretically and empirically. However, the precise role of human capital in the determination of economic growth is still unclear and remains an ongoing debate. Aghion and Howitt (1998) have categorized the modelling of human capital as a factor of growth into two major alternative frameworks. The first is the standard approach based on the Lucas (1988) and also shared by the neoclassical growth theory which treat human capital as an ordinary input in the aggregate production function. Under this structure, economic growth is determined by the accumulation of human capital and the differences in output growth across countries is due to the differences in the rate of change in human capital. The alternative framework, first proposed by the Nelson and Phelps (1966), retorts against the role of human capital as a factor input, instead suggests that human capital aids in domestic innovation and adaptation of foreign technologies. Under this structure, a country's economic growth is determined by the level of human capital, and it suggests a higher stock enhances productivity through faster innovation and through speeding technological diffusion throughout the economy.

While theoretically it is quite straightforward, empirically, the importance of human capital for economic growth generated some puzzling outcomes. Many cross-sectional studies have found a weak relationship between the accumulation of human capital and economic growth [for example, Benhabib and Spiegel (1994) and Pritchett (2001)]. Some earlier papers such as Mankiw et al.(1992) and Barro(1991) found significant outcomes for human capital as a factor input, however the papers have been criticized for their choices of human capital measures and also for their econometric specifications. Even though few studies like Temple (1999) and Krueger and Lindahl (2001) were able to reverse the puzzling findings using educational attainment data as a measure of human capital, other literatures, for instance Benhabib and Spiegel (1994), Engelbrecht(2003), and Papageorgiou(2003) started to cast importance upon the Nelson-Phelps approach. Benhabib and Spiegel (1994) confirms some considerable evidence for human capital's role in assisting technology diffusion. However the combined effect of human capital for domestic innovation and technology imitation is found to be negligible. Following this, Engelbrecht(2003) and Papageorgiou(2003) constructed and estimated a hybrid structural specification in which human capital influences growth both as a factor of production and as a facilitator of technological innovation and diffusion.

This paper uses Benhabib and Spiegel (1994) as a starting point and following Engelbrecht(2003), it uses a structural specification to examine the possibility of a dual role of human capital in determining economic growth. The study extends from the existing literatures in several important ways. While the previous studies have mostly used cross-sectional growth regression procedures, this paper utilizes panel data and estimation technique to study the growth-human capital relationship for a relatively recent period: 1980-2005. I have also incorporated a larger sample size including 25 OECD countries and 75 developing countries. In addition, possible endogeneity of the physical capital stock can derive implausible results for the basic Ordinary Lease Squares Estimation; to account for that, Instrumental Variable (IV) Estimation technique has been employed.

The main findings drawn from the empirical analysis are as follows. For the growth regressions when human capital enters the equation as a factor of production, estimated results fail to provide significant effect on output growth. Thus the results are aligned with the findings of Benhabib and Spiegel (1994). For the alternative model with the Nelson-Phelps approach, findings support the importance of the stock of human capital in explaining growth; however the combined effect for innovation and imitation term is almost negligible. The empirical evidence leads me to the prime objective of the paper which is to study the combined role of human 
capital in the determination of economic growth. From the study, the results endorse considerable evidence for both the major approaches proposed by Aghion and Howitt (1998) for modelling human capital. More precisely, the econometric specification performs better in explaining economic growth when human capital is used as an ordinary input and as a facilitator of innovation and technology diffusion simultaneously in the growth model. When subjected to different sub-sample estimations, the results show some variations across different regions. The findings also indicate that all countries may not be catching up to a single technology leader and there could be possible club convergence which is discussed in further details in the later part of the paper. The empirical evidence from this paper cannot be taken as conclusive as there are certain limitations of the study related to the proxy variables of human capital and technology. In addition, the econometric specification does not take into consideration other factors which could be essential for the diffusion of the technology (for example, international trade, foreign direct investment (FDI) etc.) .In summary, the findings of this study are indicative of requirement for future empirical work in this area with using better data and econometric specifications.

This paper is organised as follows. Section 2 describes and outlines the standard methodologies used by Benhabib and Spiegel (1994) and Engelbrecht (2003) and how I extend their models into panel econometric framework for the growth regressions. Section 3 discusses the data used in the study and the specific problems for the estimations. Section 4 presents and analyses the estimated results and the robustness check; and finally section 5 concludes the study.

\section{Methodology And Structural Specification:}

This section outlines the standard methodologies used in the previous empirical literatures and how they are extended for the empirical part of this study. The section starts with the description of the growth accounting methodology used in the Benhabib and Spiegel (1994) paper which uses human capital as a factor of production. Then I represent from the same paper the alternative model which accounts for the Nelson-Phelps approach. In section 2.3: I show how the two models can be merged to derive the hybrid model following Engelbrecht (2003). The model extensions from cross country growth specifications to panel specifications are discussed in section 2.4.

\subsection{Growth regression model with human capital as a factor of production}

In this methodology,human capital enters the production function as a factor input and the human capital's accumulation rate effects output growth. In the growth accounting framework, output per capita is specified as a function of following input factors: labour force, physical and human capital. Assuming a CobbDouglas representation, Benhabib and Spiegel (1994) show at time t, the aggregate production function can be explicitly expressed as:

(1) $Y_{t}=A_{t} K_{t}^{\alpha} L_{t}^{\beta} H_{t}^{\mu}$

Where $\mathrm{Y}$ is output, $\mathrm{K}$ is physical capital, $\mathrm{L}$ is labour force, $\mathrm{H}$ is human capital and $\mathrm{A}$ is the level of technology which grows at an exogenous rate. To express the growth relationship, Benhabib and Spiegel (1994) have taken the log differences of the above model which relates the log differences of output to the log differences of the factor inputs. It is expressed as:

(2) $\left(\log Y_{t}-\log Y_{0}\right)=\left(\log A_{t}-\log A_{0}\right)+\alpha\left(\log K_{t}-\log K_{0}\right)+\beta\left(\log L_{t}-\log L_{0}\right)+\mu\left(\log H_{t}-\right.$ $\log H O+(\log \varepsilon t-\log \varepsilon O)$

Based on this specification, human capital effects the output growth through its rate of accumulation. Benhabib and Spiegel (1994) used Equation (2) for cross country regressions, thus $Y_{0}$ is denoted as the initial level of output from the sample data.

\subsection{Growth regression model using Nelson-Phelps approach}

Benhabib and Spiegel (1994) found no significant role for human capital in determining growth under the above specification. Instead they estimated an alternative specification using the Nelson-Phelps hypothesis of modelling human capital. As discussed before, Nelson and Phelps (1966) argued that human capital represented as a factor of production is a misspecification of the growth process. Rather they suggest countries endowed with high stock of human capital are good innovators and are quicker to adapt to new ideas and technologies. So a higher level of human capital would speed up the technological diffusion process. Hence the theory strays away from the notion of exogenous rate of technological progress and allows it to depend on the level of human capital. Benhabib and Spiegel (1994) using this approach develop the alternative growth model in which total factor productivity growth relies on: (i) the level of human capital and (ii) an interaction term allowing for the catching up to the leading country's technology. Thus for a specific country i, the growth rate of total factor productivity or the technological progress at time $\mathrm{t}$ is represented as:

(3) $\frac{\dot{A}_{\mathrm{i}}(t)}{\mathrm{A}_{\mathrm{i}}(t)}=g\left(H_{i}\right)+c\left(H_{i}\right)\left[\frac{\max A_{j}(t)-A_{i}(t)}{A_{i}(t)}\right], \quad i=1, \ldots \ldots, n$. 
Where $g\left(H_{i}\right)$ is the endogenous growth rate for the innovation factor and the second component on the right hand side of the equation is the catch-up term. Both the factors are non-decreasing functions of the level of human capital $\left(H_{i}\right)$. Thus the equation (3) implies that a country with a high level of education has the potential to overtake the leading country's technology irrespective of the difference between each country's initial levels of technology. And the country can also maintain the lead provided it can sustain its educational advantages (Benhabib and Spiegel, 1994).

For a structural model following directly from the theory, Benhabib and Spiegel (1994) used the Cobb- Douglas production function:

(4) $Y_{t}=A_{t}\left(H_{t}\right) K_{t}^{\alpha} L_{t}^{\beta}$

Where, $Y_{t}$ is the per capita income, $K_{t}$ is the physical capital, $L_{t}$ is the labour force and $A_{t}$ is the level of technology which is a function of human capital $H_{t}$. In similar manner to equation (2), the growth equation is expressed by taking the log differences:

$$
\text { (5) }\left(\log Y_{t}-\log Y_{0}\right)=\left[\log A_{t}\left(H_{t}\right)-\log A_{0}\left(H_{t}\right)\right]+\alpha\left(\log K_{t}-\log K_{0}\right)+\beta\left(\log L_{t}-\log L_{0}\right)+\left(\log \varepsilon_{t}-\right.
$$
$\left.\log \varepsilon_{0}\right)$

Contrary to equation (2) in which change in the level of technology or the growth accounting residual is exogenously determined, in the above equation (5), the first component specified as the total factor productivity growth now incorporates the Nelson-Phelps approach. Hence the change in the level of technology now depends on the level of human capital for the ability to innovate and on an interaction term that relates human capital and the technological lag for the catch-up factor. For the difficulty of observing technology, Benhabib and Spiegel (1994) used output per capita to roughly proxy for the level of technology. Thus the structural specification for the growth of total factor productivity for a country iis as follows:

(6) $\left[\log A_{t}\left(H_{t}\right)-\log A_{0}\left(H_{t}\right)\right] i=c+g H_{i}+m H_{i}\left[\frac{\left(Y_{\max }-Y_{i}\right)}{Y_{i}}\right]$

Where $\mathrm{c}$ is the exogenous technological progress, $g H_{i}$ is the domestic innovation term and $m H_{i}\left[\left(Y_{\max }-Y_{i}\right) / Y_{i}\right]$ is the interaction term reflecting the technology diffusion from abroad. Rearranging equation (6) gives:

(7) $\left[\log A_{t}\left(H_{t}\right)-\log A_{0}\left(H_{t}\right)\right] i=c+(g-m) H_{i}+m H_{i}\left(\frac{Y_{\max }}{Y_{i}}\right)$

This is then inserted in equation (5) to yield:

(8) $\left(\log Y_{t}-\log Y_{0}\right)=c+(g-m) H_{i}+m H_{i}\left(\frac{Y_{\max }}{Y_{i}}\right)+\alpha\left(\log K_{t}-\log K_{0}\right)+\beta\left(\log L_{t}-\log L_{0}\right)+\left(\log \varepsilon_{t}-\right.$ $\left.\log \varepsilon_{0}\right)$

From the above equation, it can be seen that the impact of the stock of human capital on growth would depend on the cumulative effect of the domestic innovation and the technology diffusion terms

\subsection{The Hybrid Model:}

Papageorgiou (2003) and Engelbrecht (2003) stressed upon the hypothesis of multiple roles of human capital for determining economic growth. It implies that human capital is an important factor of growth for its role as an input in the production function and as an input for technology innovation and technology diffusion. If there exist more than one mechanism through which human capital effects growth, modelling based on only either one of the approaches would lead to omitted variable bias. To account for both the theories, Engelbrecht (2003) constructed a hybrid model allowing human capital to enter as a production factor of final output and as a basis of technology innovation and diffusion. So starting with the basic Cobb-Douglas representation:

(9) $Y_{t}=A_{t}\left(H_{t}\right) K_{t}^{\alpha} L_{t}^{\beta} H_{t}^{\mu}$

The notations remain the same as the above equations. Here human capital enters the aggregate production function both as a factor input and as a determinant of technological progress. Analogously taking the log differences, the econometric framework can be represented as:

$$
\begin{aligned}
& (10)\left(\log Y_{t}-\log Y_{0}\right)=\left[\log A_{t}\left(H_{t}\right)-\log A_{0}\left(H_{t}\right)\right]+\alpha\left(\log K_{t}-\log K_{0}\right)+\beta\left(\log L_{t}-\log L_{0}\right)+\mu\left(\log H_{t}-\right. \\
& \log H O+(\log \varepsilon t-\log \varepsilon 0)
\end{aligned}
$$

And inserting the specification of the total factor productivity growth (7) gives the hybrid model:

$$
\begin{aligned}
& (11)\left(\log Y_{t}-\log Y_{0}\right)=c+(g-m) H_{i}+m H_{i}\left(\frac{Y_{\max }}{Y_{i}}\right)+\alpha\left(\log K_{t}-\log K_{0}\right)+\beta\left(\log L_{t}-\log L_{0}\right)+ \\
& \mu\left(\log H_{t}-\log H_{0}\right)+\left(\log \varepsilon_{t}-\log \varepsilon_{0}\right)
\end{aligned}
$$

\subsection{Panel Specification of the Growth Models:}

Benahbib and Spiegel (1994) and Engelbrecht (2003) use the above growth regression models for cross-country estimations with time averaged data. The advantage of time average data is that it allows 
reducing the measurement errors associated with the data and such measurement errors can create potential noise (Engelbrecht, 2003). However time-averaged data also can lead to loss of information and thus I extend the study using panel data for a relatively recent time- interval. The advantage of using panel data is it provides more information and variability. It increases the precision of the estimation for the presence of higher number of observations. Other advantage of panel data includes allowing consistent estimation with fixed effects model which accounts for unobserved cross-sectional heterogeneity. In addition, it also allows Instrumental Variable estimation with availability of lagged variables for instruments.

So under the Cobb-Douglas representation, for the first approach with factor input human capital, nominal income of country $i$ at time $\mathrm{t}$ can be expressed as $Y_{i t}=A_{i t} K_{i t}^{\alpha} L_{i t}^{\beta} H_{i t}^{\mu}$ and in similar manner: $Y_{i t}=A_{i t}\left(H_{i t}\right) K_{i t}^{\alpha} L_{i t}^{\beta}$ and $Y_{i t}=A_{i t}\left(H_{i t}\right) K_{i t}^{\alpha} L_{i t}^{\beta} H_{i t}^{\mu}$ for the Nelson-Phelps growth model and the hybrid model respectively. The panel specification of the equation (2), (5) and (8) for the growth models with log differences are as follows:

- With the accumulation of Human Capital:

(12) $\left(\log Y_{i t}-\log Y_{i t-1}\right)=\left(\log A_{i t}-\log A_{i t-1}\right)+\alpha\left(\log K_{i t}-\log K_{i t-1}\right)+\beta\left(\log L_{i t}-\log L_{i t-1}\right)+$ $\mu\left(\log H_{i t}-\log H_{i t-1}\right)+\left(\log \varepsilon_{i t}-\log \varepsilon_{i t-1}\right)$

-With the stock of Human Capital:

(13) $\left(\log Y_{i t}-\log Y_{i t-1}\right)=c+(g-m) H_{i t}+m H_{i t}\left(\frac{Y_{\max } t}{Y_{i t}}\right)+\alpha\left(\log K_{i t}-\log K_{i t-1}\right)+\beta\left(\log L_{i t}-\right.$
$\log L i t-1+(\log \varepsilon i t-\log \varepsilon i t-1)$

-With both the accumulation and stock of human capital:

(14) $\left(\log Y_{i t}-\log Y_{i t-1}\right)=c+(g-m) H_{i t}+m H_{i t}\left(\frac{Y_{\max } t}{Y_{i t}}\right)+\alpha\left(\log K_{i t}-\log K_{i t-1}\right)+\beta\left(\log L_{i t}-\right.$

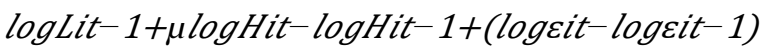

Equation (12), (13) and (14) are the econometric specifications used in this paper for the empirical estimations. The primary regression technique involves ordinary least squares with White's heteroskedasticity corrected errors which takes into consideration the heteroskedasticity prevalent in cross sectional observations. Since this study is using panel data which is a combination of both cross sectional and time series data, there can be possible serial correlation along with heteroskedasticity in the errors. Thus to derive robust standard errors of regression coefficients, I have also tested estimations with panel corrected standard errors. Giving importance to Temple (1999) emphasis on the effect of outliers, robust regression is conducted which down weights the effect of outliers using iterative reweighted least squares (Yaffee, 2002). The growth regressions assume that the all countries have the same production function which implies there is no cross-sectional heterogeneity among the sample countries. Harberger (1987) counterviewed the above assumption for the concern of cross-sectional parameter heterogeneity and advocated the use of fixed effects estimator. Presence of cross-sectional heterogeneity can cause the basic pooled regression to be biased and inconsistent. With the advantage of panel data which allows taking into account differences in the production function, I therefore looked into the fixed effects estimation technique for possible heterogeneity. Caselli et al (1996) proposed that the physical capital stock is endogenous in the growth equations. The choice variable physical capital is derived from the rate of investment, and economic growth is likely to influence the optimal rate of investment which could lead to physical capital being possibly endogenous. To take into consideration the endogeneity problem, Instrumental Variable technique is implemented to correct the potential bias using lagged logged differences of physical capital and output as instruments.

\subsection{Data}

\section{Data And Specific Limitations}

The estimations in this paper involve a total sample of 100 (25 OECD and 75 developing) countries for the period between 1980 and 2005. The countries and the time period are determined based on the data availability. The dataset contains observations on gross domestic product per capita (GDP per capita), total physical capital stock, labour force and the average years of schooling along with disaggregated average for each level of schooling (primary, secondary and tertiary). GDP per capita or output per capita is retrieved from the World Development Indicators (2011).

GDP per capita or output per capita is retrieved from the World Development Indicators (2011). The labour force data is taken from the Penn World Table (7.1). Theoretically human capital has not been defined in a specific manner. It is an extensive theoretical concept which can be summarised as the skills and resources embedded in each individual. Schütt (2003) describes human capital as the knowledge, skills and attributes of people that are pertinent for economic activity. However empirical studies have mostly resorted to using formal education as a rough proxy of human capital for the unavailability of data encompassing all the measures of 
human capital. Engelbrecht(2003) explains that all the measures of human capital contain some kind of measurement errors and a particular proxy is suitable if it is related to the human capital stressed by the theory. With empirically education being narrowly defined as the proxy for human capital, I have used the Barro and Lee (2010) dataset on educational attainment for the measure of human capital. Cohen and Soto (2007) criticize the Barro and Lee (1993) data for measurement errors and for using homogenous mortality rate. I still primarily used the Barro and Lee (2010) data as this updated version has taken into consideration reducing the measurement errors with using consistent census data and also has the sorted the issue of the mortality rate. In addition, with the disaggregated data on average years of schooling, it allows me to use the different levels of schooling as alternative measures for the sub-categories of human capital stressed by the different theories

Of considerable interest is the data on the stock of physical capital. It needs to be constructed from the investment flow data. The main references for the construction of the stock of capital are the papers by Bernanke and Gurkaynak( 2001) and Safdari et al. (2010). Bernanke and Gurkanayak (2001) retrieved the investment flow data from the Penn World Table (6.0) to derive the capital stock by using the perpetual inventory calculation method. Based on their approach, Safari et al. (2010) extended five-yearly data up to 2005 which is used for the estimations for this study.

\subsection{Specific limitations for the growth regressions:}

Before discussing the empirical results, it is important to highlight some of the specific problems related to the data, proxy measures and econometric specifications.

\subsubsection{Measurement Errors of Human capital:}

Measurement errors in the data of the proxy for human capital are pervasive. As discussed before, the existing literatures have stressed upon the different possible errors in the measurement of human capital. Earlier studies use enrolment rates or literacy rates which are argued as inappropriate proxy measures by Pritchett (2001). With educational system generalised as the source of acquiring knowledge, human capital stock is mostly characterized by schooling attainment data. But whether this data constitutes to the rate of investment in human capital is questionable. Also, as pointed by Aghion and Howitt (1998), the proxy should be determined by the type of human capital that goes into the production function. Other alternative measures, for example, research and development expenditure or public expenditure on human capital may be more suitable to represent the investment in human capital in the aggregate production function. Tiruneh and Radvansky (2009) in their paper use research and development ( $\&$ \&) expenditure as one of the alternative measure for human capital accumulation. For a sample of European countries, they found R \& D expenditure to be positively related to economic growth. I could not extend the investigation for this paper due to the lack of data available for the R \& $\mathrm{D}$ expenditure of the developing countries. Hence I leave this for future research to explore whether R\&D expenditure as a proxy of human capital gives more a convincing result for determining economic growth.

The educational attainment data primarily focuses on the quantity measures of human capital rather than the quality measures. Due to the heterogeneity of the countries in the data, there is a high likelihood of variation in the quality of education across the different countries that can cause differences in the stock of human capital. Hanushek and Kimko (2000) acknowledge the importance of quality measure of human capital as a key for determining a positive liaison between human capital and growth. Instead of using schooling data, they have used internationally comparable mathematics and science test scores to reflect the qualitative difference in the labour force. Estimated results show a strong positive correlation between growth and the quality measure. However the problem with the Hanushek -Kimko data is it only considers the qualitative aspect of human capital not the quantitative measures. Hence for the time being, the quality adjusted schooling data is preferable for empirics. However, for future reference, construction of data accounting for both qualitative and quantitative variation should be of high priority.

On a different note, Machin and Macnally (2007) pointed out that individuals are studying subjects in higher education which may not be required in the output market. This can imply that the expansion of tertiary education may not reflect the increase in the level of human capital that can contribute to the output growth. Also the formal education measure disregards the human capital that could be attained from other sources such as vocational training or through job experience (Engelbrecht, 2003).

\subsubsection{Proxy for technology catch-up term:}

As discussed previously, Benhabib and Spiegel (1994) use per capita GDP as a rough approximation for the technology gap. Following them, Engelbrecht(2003) also applies the same approach to determine the technology diffusion factor in the hybrid model. Both the papers implement cross-sectional regression approach using data from the period between 1965 and 1985.They have assumed USA to be the technology leader and thus used 1965's GDP per capita of USA to proxy for the technology gap. However in the context of this paper, which is using data period 1980-2005, USA's GDP per capita is not the highest in 1980. Also based on 
the notion of using highest GDP per capita to represent the technology leader, with the use of five yearly panel data, the catch-up component is operating at higher frequency which requires adjusting for $Y_{\max }$ for each period t.

Clearly from the fig (1), it can be seen the highest GDP per capita is represented by different countries' GDP. For the periods 1980 and 1985 it is Switzerland and for the latter periods it is Luxembourg. GDP per capita may not be a perfect proxy for technology as there can be other factors that can enhances it; for instance, for Luxembourg, the high GDP per capita is possibly due to the financial services which account for a major portion of the nation's GDP.

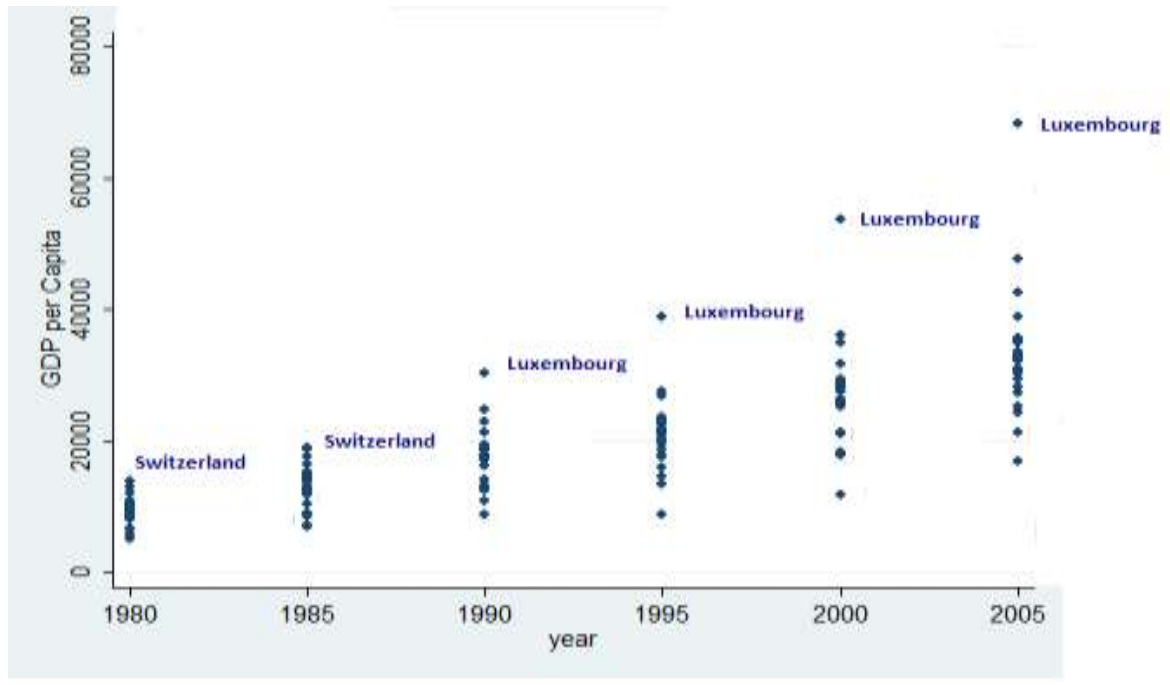

Figure1: Year-wise GDP per capita

With the view of USA being the worldwide leader of science and technology and keeping in parallel with the previous studies, I still represent USA as the technology leader and use its' GDP per capita to approximate for the technology gap in the panel estimation framework. However, future research should be directed to this area to derive a more suitable proxy to represent the science and technology endowed in a country.

The sample used in this paper consists of both OECD and developing countries from different regions of the world. When testing for such a diverse sample, it is important to stress on the fact that all the countries may not be catching up to the USA's technology as there could be evidence of possible 'growth clubs'. It implies all the countries may not be converging to a single economy but rather sub-group of economies are converging or catching-up to one another or may not be converging towards any economy at all. Ben-David (1994) found some evidence for convergence clubs among the wealthier countries and among the low income countries. This issue has not been stressed upon in the previous literatures for the Nelson-Phelps catch-up factor. To take this into consideration, for estimations using the developing countries' sub-samples, I have used the average GDP per capita of the OECD countries to proxy for the technology gap. Section (4.3) outlines this in more detail.

\subsubsection{Mechanisms for technology transfer:}

It is important to note that there could be few reasons why the imitation term is not significant even though there is evidence of considerable increase in the stock of human capital. As the Nelson-Phelps hypothesis implies, a country endowed with a high level of human capital will be able to adapt to foreign technology faster than a country with a relatively lower level of human capital. However there should be some channels through which the transmission of technology can occur between the countries. Grossman and Helpman (1991) cast importance upon international trade as the means through which there can be spill over effects. The imitation of foreign spill overed technologies can then raise the productivity of an economy. Other literatures such as Liu (2008) and Borensztein et al. (1998) support the role of Foreign Direct Investment (FDI) as the channel for technology transfers. Hence to derive positive impact of human capital on growth through technology diffusion, a high stock of human capital should also be complemented by institutional settings and policies which allow for mechanisms through which the technology can transfer from one economy to another. Engelbrecht (2002) used trade-weighted foreign R\&D capital stock and import share as measures of stock of knowledge contained in a country's trade and trade openness respectively in the total factor productivity framework to investigate how international trade can aid in output productivity through technology diffusion. 
The results generate considerable support for knowledge spill over through trade and for the importance of human capital in the absorption of the foreign knowledge. I could not incorporate the different mechanisms of technology transfer in the econometric framework for the lack of updated data for the measures for technology embodied trade or FDI.

\section{Empirical Results}

For the empirical estimations, I first evaluate the econometric framework with human capital as a factor input following the Benhabib and Spiegel (1994) specification. Then in similar approach to Benhabib and Spiegel (1994) and Engelbrecht(2003), I separately estimate the structural equation which models human capital as a facilitator of domestic innovation and technology diffusion. I then extend my study to investigate if the alternative hybrid model combining the two approaches gives better results for the growth-human capital relationship. To see how different countries behave in the hybrid growth model, I conduct estimations on different sub-group of countries as well.

From the tables, regression (1) shows the result for Ordinary Least Squares (OLS) with White's heteroskedasticity corrected errors. The regressions with panel corrected standard errors show no presence of serial correlation in the errors and thus the results are exactly similar to the robust OLS regressions. Therefore I have excluded them from my main findings. To test for the country-specific effect, I implement the fixed-effects estimation technique. For the sample data, the joint F-test for heterogeneity rejects the presence of crosssectional heterogeneity. With a diverse sample of countries used in this study, the rejection of heterogeneity is somewhat troubling. One of the possible reasons for the test results could be due to the presence of greater number of developing countries in the sample. Fixed effects estimation utilizes within variation and not the between variation of the countries. However, most of the developing countries did not have considerable variation through time. Also the demographics such as corruption, education system, governmental issues etc. are quite similar among the countries, which are why it is possible the joint $\mathrm{F}$ test could not capture any crosssectional heterogeneity. Fixed Effects estimation even tough allows taking into concern the heterogeneity problem, it has few drawbacks. One of the problems related to this study is the possibility of inconsistent estimation for relatively smaller time dimension $\mathrm{T}$ and lager $\mathrm{N}$ (cross sectional data). To account for the country specific heterogeneity, the regression requires estimating $\mathrm{N}$ extra parameters. It uses up the degrees of freedom which is considerable loss of efficiency with a small time dimension $\mathrm{T}$. With the potential problems and with the insignificance for heterogeneity, fixed effects estimations are not used for interpretation purposes and have been excluded from the main findings. Instead to investigate the likely heterogeneity, I have split the entire data into samples of countries with similar characteristics and by regional sub-samples for estimation. Finally, robust regressions and IV regressions accounting for the problems of outliers and endogeneity respectively are reported as regression (2) and regression (3) in the tables

\subsection{Results: Human Capital as a factor input}

Prior to the formal regressions, to explore the correlation between the variables, univariate relationships are outlined between the log differences in output and log differences in inputs. From fig 2, it can be seen that $\log$ differences in physical capital depicts a positive correlation with the log differences in output. For labour, the correlation is very close to zero. The noteworthy observation from the figure is that the correlation between the log differences in human capitaland the log differences in output is almost negative. The regression output gives similar result.

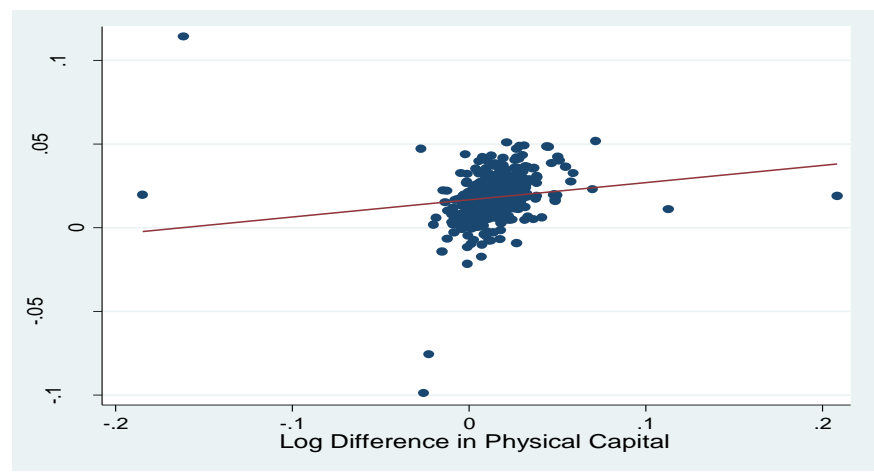

(a)

Output vs. Physical Capital 


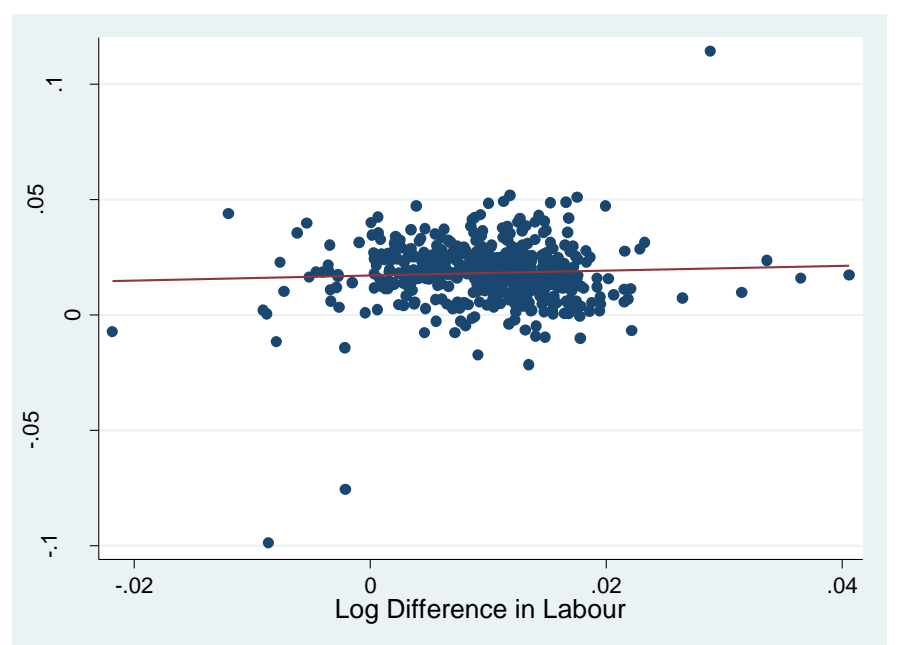

(b)

Output vs. Labour

(c)

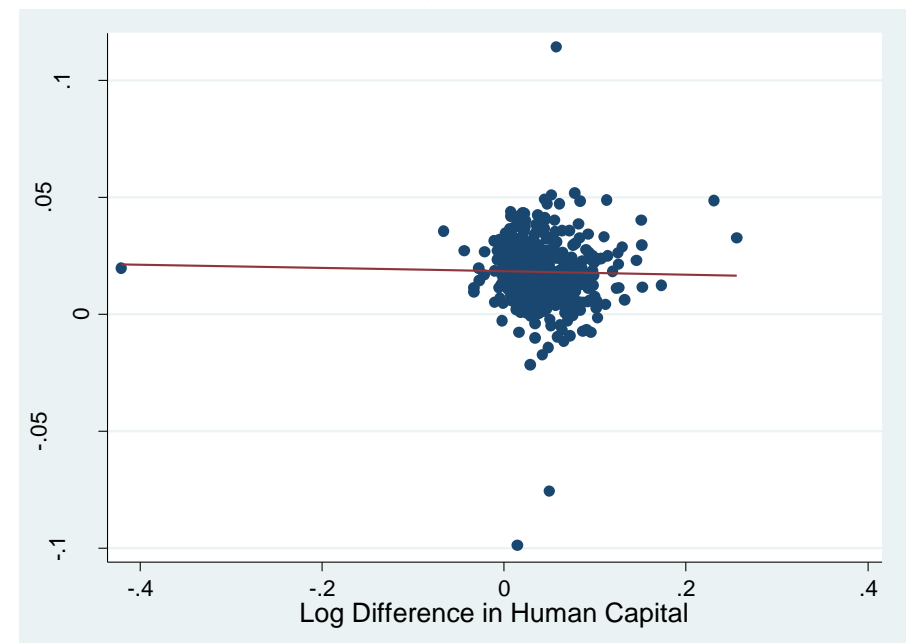

(d) Output vs. Human Capital

Figure 2: Growth in output vs. factor accumulation

Table 4.1: Estimated results for the entire sample: Growth Specification 12

\begin{tabular}{|l|l|l|l|}
\hline \hline & OLS (1) & Robust Regression (2) & IV Regression (3) \\
\hline \hline DK & $.10407(.10919)$ & $.40627(.02399)$ & $.21074 *(.06408)$ \\
\hline $\mathrm{DL}$ & $.12139(.16738)$ & $.23812(.06833)$ & $.25050 *(.10623)$ \\
\hline $\mathrm{DH}$ & $-.01510(.01431)$ & $.00995(.01136)$ & $.06793 *(.02571)$ \\
\hline Constant & $.01595^{*}(.00205)$ & $.01512 *(.00088)$ & $.01443 *(.00160)$ \\
\hline \hline
\end{tabular}

Note: The dependent variable is DY. DX denotes the growth rate of variable X. The Standard errors are given in parentheses. $\left({ }^{*}\right),\left({ }^{* *}\right)$ and $\left({ }^{* * *}\right)$ denotes that the estimates is statistically significant at $1 \%, 5 \%$ and $10 \%$ level respectively.

From the Table 4.1, OLS estimation with White's heteroskedasticity corrected standard errors shows that all the coefficients are statistically insignificant. Even though the physical capital and the labour force enters the equation with the expected positive point estimates, human capital depicts a negative relationship with output growth when it enters the equation as a factor input. The residual diagnostic plot post estimation shows some reasonably high residual values that could be cumulatively an evidence of outlier effect. In order to deal with this, I estimate regression (2). The result shows no noteworthy difference except for a very high coefficient estimate for the change in the physical capital. However, all the result still remains statistically insignificant. 


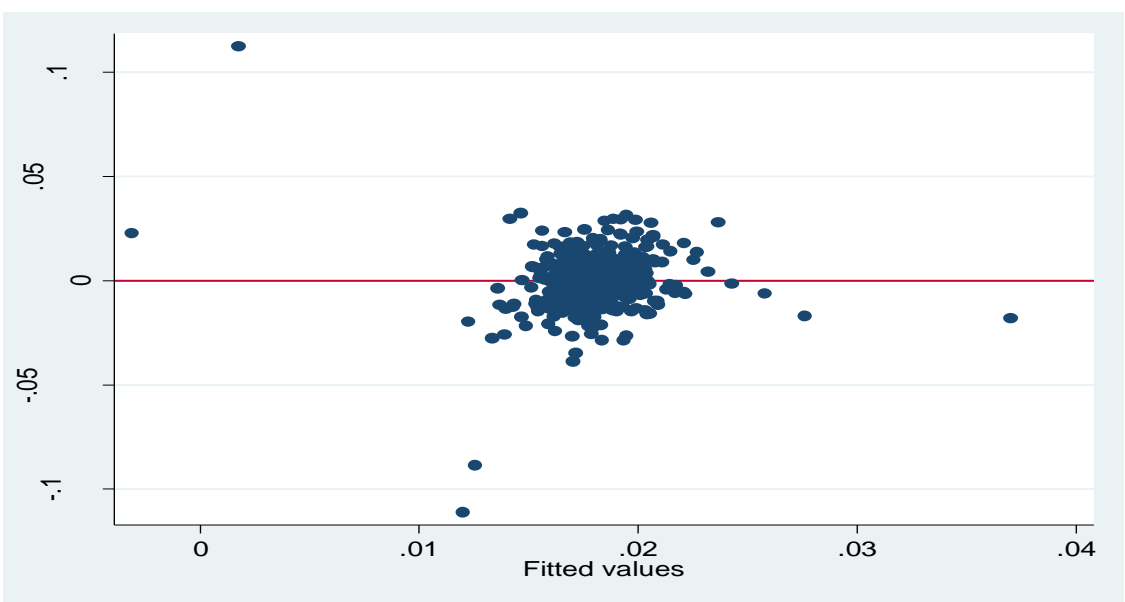

Figure 3: Residual plot

After taking into consideration the endogeneity problem, regression (3) generates coefficients significant at $1 \%$ level. The parameter estimates for both physical capital and labour are with the expected signs; however human capital is still negatively related to growth. I conduct few diagnostic tests post IV estimation to test for the validity of the regression. Results support the use of IV regression as physical capital is indeed endogenous. Therefore I use Instrumental variable estimations (regression3) as the benchmark for interpretation purposes. And based on regression (3) table 4.1, accumulation of human capital is negatively related to output growth.

\subsection{Results-Human Capital in the Nelson Phelps Approach}

Analogous to the Benhabib and Spiegel (1994) findings, this paper also generates negative coefficient estimate for the rate of accumulation of human capital using panel data and using different estimation techniques. To investigate the claim by Nelson and Phelps (1966), econometric specification (13) is estimated and the results are reported in table 4.2. I use the same Barro-Lee data on average level of schooling for the measure of human capital. Again prior to the formal regressions, I look at the univariate relationships between the output growth and the regressors.

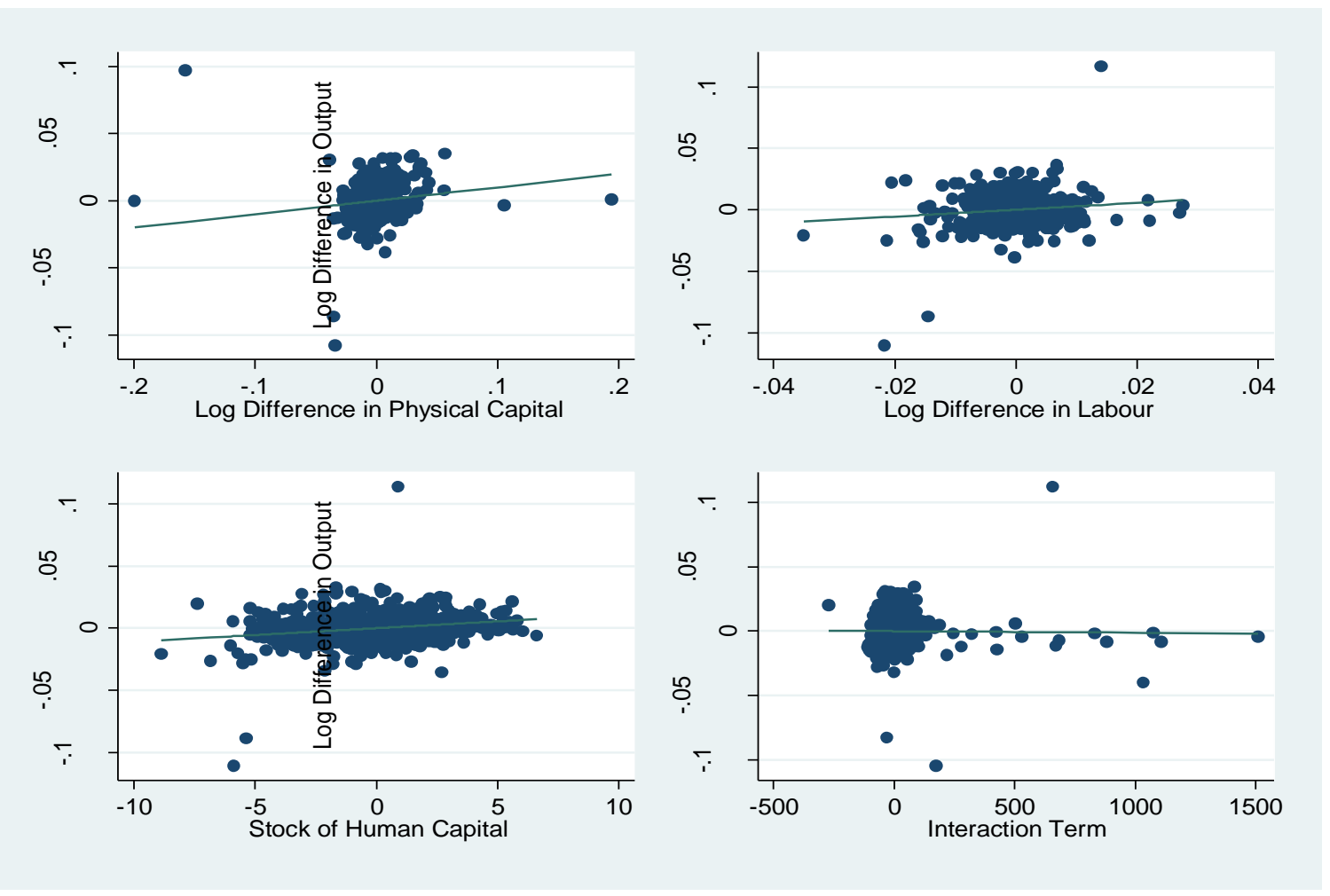

Fig 4: Growth in output vs. choice variable 
Contrary to the correlation with $\log$ differences in human capital which was almost negative, log differences in output is positively correlated with the stock of human capital. For the interaction term between the level of human capital and the technology gap, the correlation with the log differences in output is almost zero. Regression (1) from Table (4.2) illustrates that domestic innovation term enters the growth equation with a positive and highly significant coefficient. However the technology catch-up component seems to be statistically unimportant. Extending the estimations to robust regression does not affect the result both qualitatively and quantitatively except for a relatively higher coefficient value for the physical capital growth. After taking care of the endogeneity problem, estimates for both physical capital and labour enter with significant consensus signs. The domestic innovation term still remains positive and highly significant. The point estimate for the technology diffusion term is now positive, however it remains insignificant. Also, the coefficient value is almost close to zero which is analogous to the relationship outlined in fig 4.

Table 4.2-Estimated results for the entire sample: Growth Specification 13

\begin{tabular}{|l|l|l|l|}
\hline \hline & OLS (1) & Robust Regression (2) & IV Regression (3) \\
\hline \hline DK & $.09976(.10084)$ & $.40252(.02386)$ & $.16394 *(.06392)$ \\
\hline $\mathrm{H}$ & $.27991(.18358)$ & $.09804(.07159)$ & $.35431 *(.10703)$ \\
\hline $\mathrm{H}\left(\mathrm{Y}_{\text {max }} \mathrm{Y}\right)$ & $.001010 *(.00029)$ & $.00065 *(.00017)$ & $.00130 *(.00027)$ \\
\hline Constant & $-1.2 \mathrm{e}-06(8.05 \mathrm{e}-06)$ & $-3.4 \mathrm{e}-06(3.01 \mathrm{e}-06)$ & $2.6 \mathrm{e}-06(4.36 \mathrm{e}-06)$ \\
& $.00721 * *(.00376)$ & $.00955^{*}(.0015554)$ & $.00302(.00256)$ \\
\hline \hline
\end{tabular}

Note: The dependent variable is DY. DX denotes the growth rate of variable X. The Standard errors are given in parentheses. $\left({ }^{*}\right),\left({ }^{* *}\right)$ and $\left({ }^{* * *}\right)$ denotes that the estimates is statistically significant at $1 \%, 5 \%$ and $10 \%$ level respectively.

To stress upon the claim by Aghion and Howitt (1998) for the importance of higher level of education for technology diffusion and innovation, I re-estimate the growth specification (13) with using the average tertiary level of schooling instead of the overall schooling average for the measure of human capital. Table 4.3 reports the estimated outputs. The results show considerably little significant change. The coefficient for the domestic innovation term increases slightly. With the instrumental variable regression, there is a moderate increase in the point estimate for the technology diffusion term; however the magnitude effect is still very small and the coefficient remains statistically insignificant.

Table4.3-Estimated results for the entire sample using tertiary education: Growth Specification 13

\begin{tabular}{|l|l|l|l|}
\hline \hline & OLS (1) & Robust Regression (2) & IV Regression (3) \\
\hline \hline DK & $.10044(.10534)$ & $.40329(.02398)$ & $.19176^{*}(.06430)$ \\
\hline $\mathrm{HL}$ & $.17144(.17437)$ & $.21077(.06958)$ & $.23964 * *(.10574)$ \\
\hline $\mathrm{H}(\mathrm{Y}$ max $\mathrm{Y})$ & $.00802 *(.00297)$ & $.00287(.00213)$ & $.00885 *(.00329)$ \\
\hline Constant & $7.0 \mathrm{e}-06(.00017)$ & $-5.5 \mathrm{e}-05(.00009)$ & $8.4 \mathrm{e}-05(.00013)$ \\
\hline \hline
\end{tabular}

Note: The dependent variable is DY. DX denotes the growth rate of variable X. The Standard errors are given in parentheses. $\left({ }^{*}\right),\left({ }^{* *}\right)$ and $\left({ }^{* * *}\right)$ denotes that the estimates is statistically significant at $1 \%, 5 \%$ and $10 \%$ level respectively.

The combined effect of human capital is very little for the specification incorporating the NelsonPhelps approach. The estimated results seem to agree upon the Pritchett (2001) micro-macro paradox for the human capital and growth relationship. Before resorting to the paradox, I extend to the main objective of my study to examine the concurrent effects of human capital on economic growth and therefore estimate equation specification (14). 


\subsection{Results- Human Capital in the hybrid model}

In this part, I present the estimations conducted with using the hybrid model. Human capital is considered to effect economic growth both in level and in difference terms. I use the average tertiary education attainment as the proxy measure for the human capital relevant for domestic innovation and technology diffusion following the claim by Aghion and Howitt (1998). The average level of the total education attainment is used for the human capital contributing to the output production.

\begin{tabular}{|c|c|c|c|}
\hline & OLS (1) & Robust Regression (2) & IV Regression (3) \\
\hline$\overline{\mathrm{DK}}$ & $.10043(.10548)$ & $.40371(.02410)$ & $2.200750 *(.06459)$ \\
\hline $\mathrm{DL}^{-}$ & $.17139(.17310)$ & $-.20667(.07037)$ & $.27336 * *(.10730)$ \\
\hline $\mathrm{DH}$ & $.00006(.01407)$ & $.00534(.01221)$ & $.04983 * *(.02812)$ \\
\hline $\mathrm{H}$ & $.00802 *(.00315)$ & $.00252(.00228)$ & $.00621 * *(.00361)$ \\
\hline $\mathrm{H}(\mathrm{Ymax} \mathrm{Y})$ & $7.0 \mathrm{e}-05(.000165)$ & $-5.2 e-05(.000090)$ & $.00011(.00013)$ \\
\hline Constant & $.013110 *(.00277)$ & $.01416 *(.00119)$ & $.01194 *(.00208)$ \\
\hline
\end{tabular}

Note: The dependent variable is DY. DX denotes the growth rate of variable X. The Standard errors are given in parentheses. ( $*),(* *)$ and (***) denotes that the estimates is statistically significant at $1 \%, 5 \%$ and $10 \% 1$ evel respectively.

In regression 1, Table (4.4), point estimates for the rate of accumulation of human capital, domestic innovation and the imitation variable enter with positive coefficients. However except for the domestic innovation term, other parameter estimates are statistically insignificant. Extending to the robust regression (2) to account for outliers, the result shows that the log differences in labour enters with a negative coefficient which is not aligned with the consensus value. Also, both the human capital accumulation rate and the catch-up component generate negative point estimates. Conversely, the qualitative results still remain unaffected meaning they all are statistically insignificant, hence much cannot be inferred from the estimated regression. After accounting for the endogeneity problem of the physical capital, regression (3) presents that log differences in both physical capital and labour enter with the expected positive significant coefficients. More importantly, the estimate for the log differences in human capital is now positive and statistically significant at $10 \%$ level. The result is contrary to the previous empirical finding in which human capital entered the econometric specification solely as a factor of production. The point estimates for the innovation term and technology diffusion are positive but it is not significant for the latter.

Based on the results for the entire sample, the technology imitation term turns out to be unimportant. However the study still supports the view that further research should be focused on building econometric models to combine the different impacts of human capital as there is a considerable combined effect of human capital on growth when the hybrid model is used.

To investigate how different countries are affected, I divided the entire sample into the two following groups: OECD countries and developing countries and re-estimate the equation specification (14) of the hybrid model for each group. Similar to prior estimation, I have used the higher level of schooling data to proxy for the technology innovation and the diffusion term and the average years of schooling to proxy for the factor input.

Table 4.5 - Estimated results for the OECD Countries: Hybrid Growth Specification 14

\begin{tabular}{|l|l|l|l|}
\hline \hline & OLS (1) & Robust Regression (2) & IV Regression (3) \\
\hline \hline DK & $.01280(.00863)$ & $.00856(.02500)$ & $.02090(.04692)$ \\
\hline $\mathrm{DH}$ & $.64011^{*}(.16426)$ & $.64325 *(.14701)$ & $.72188^{*}(.13769)$ \\
\hline $\mathrm{H}$ & $-.05628(.02740)$ & $-.05571(.03073)$ & $-.03708(.02944)$ \\
\hline $\mathrm{H}(\mathrm{Ymax} / \mathrm{Y})$ & $-.02230 *(.00550)$ & $-.02367 *(.00643)$ & $-.02131 *(.00609)$ \\
\hline Constant & $.00784 *(.00366)$ & $.00845 *(.00411)$ & $.00938^{* *}(.00381)$ \\
\hline \hline
\end{tabular}

Note: The dependent variable is DY. DX denotes the growth rate of variable X. The Standard errors are given in parentheses. $\left(^{*}\right),\left({ }^{* *}\right)$ and $\left({ }^{* * *}\right)$ denotes that the estimates is statistically significant at $1 \%, 5 \%$ and $10 \%$ level respectively. 
Table (4.5) present no notable quantitative and qualitative difference among the results generated through different estimation techniques. For endogeneity problem, I use regression (3) for interpretation purposes. Coefficient estimates for both physical capital and labour growth enter the equation with the expected signs; however the growth of physical capital is statistically insignificant. For the OECD countries, the technology catch-up component is now positive and statistically significant at 5\% level, which implies there is evidence of convergence among the OECD countries and the possibility of 'club convergence'. Somewhat troubling are the coefficient estimates for the domestic innovation term and the human capital growth. The technology innovation point estimate is negative and significant. Benhabib and Spiegel (1994) indicated that the level of education only has a significant positive effect on economic growth when countries start off from a low level of human capital. For OECD countries which have similar attributes and relatively higher levels of human capital, it is hard to derive a positive impact on growth from the stock of capital. Human capital growth (DH) is negatively related to output growth but it is statistically insignificant. This could imply that for wealthier and developed countries represented by the OECD countries, output growth is not effected by the rate of accumulation of human capital. Alternatively, as indicated above, it could be also that for the OECD countries with existing high level of education, change in educational attainment may not be a good proxy to represent the investment in human capital. In summary, for the OECD countries, there is evidence of technology catch-up which can positively impact output growth. However, the estimation does not support evidence for positive effect of domestic innovation and human capital growth. Possible reasons could be the countries' output is unaffected by the variables or the proxies are not suitable measures for human capital representations.

Table4.6 - Estimated results for the developing countries: Hybrid Growth Specification 14

\begin{tabular}{|l|l|l|l|}
\hline \hline & OLS (1) & Robust Regression (2) & IV Regression (3) \\
\hline \hline DK & $.15202(.18163)$ & $.39584^{*}(.03538)$ & $.21900^{*}(.07315)$ \\
\hline $\mathrm{DL}$ & $.25355(.23010)$ & $-.17499(.23534)$ & $.30751(.25065)$ \\
\hline $\mathrm{H}$ & & $.00730(.01368)$ & $.04226^{* * *}(.02643)$ \\
\hline $\mathrm{H}(\mathrm{Y}$ max $\mathrm{Y})$ & $.01122(.01561)$ & $.00451(.00402)$ & $.00786 * * *(.00455)$ \\
\hline Constant & $.00862 * * *(.00465)$ & $.00003(9.83 \mathrm{e}-05)$ & $.00014(.00019)$ \\
\hline \hline
\end{tabular}

Note: The dependent variable is DY. DX denotes the growth rate of variable X. The Standard errors are given in parentheses. $\left({ }^{*}\right),\left({ }^{* *}\right)$ and $\left({ }^{* * *}\right)$ denotes that the estimates is statistically significant at $1 \%, 5 \%$ and $10 \%$ level respectively.

Table (4.6) presents the estimated outputs for the developing countries from the sample. Using USA as the technology leader and based on the instrumental variable regression, the results show that both technology innovation and accumulation of human capital are positive and significant in explaining output growth. Hence the estimation suggests that the developing countries benefit from the contribution of human capital for output production. Also the result reinforces the claim by Benhabib and Spiegel (1994) regarding the level of education having positive impact on growth for the countries that start off with relatively low levels of human capital. Conversely, the point estimate for the technology catch-up is found to be insignificant. Before concluding that the developing countries do not benefit from technology diffusion, I further investigate if the insignificant result is due to possibility of club convergence. It may be that the developing countries do not catch up to the 'technology leader' which is represented by USA in this study. It could be that they converge to a different countries' technology. However, it is very difficult to inspect for empirical purposes which economy the developing countries are converging to or if they are converging to any economy at all.

Therefore, in the empirical estimation for the developing countries, instead of using USA as the technology leader and its GDP per capita as the proxy for the technology gap, I have taken the OECD countries cumulatively as the technology leader and calculated the average OECD GDP per capita for the measure of the technology gap. 
Human Capital and Economic Growth: An empirical investigation using panel data

Table 4.7 - Estimated results for the developing countries using OECD countries as the technology leader: Hybrid Growth Specification 14

\begin{tabular}{|l|l|l|l|}
\hline \hline & OLS (1) & Robust Regression (2) & IV Regression (3) \\
\hline \hline DK & $.16268(.15401)$ & $.39942 *(.03533)$ & $.22640^{*}(.07144)$ \\
\hline $\mathrm{DL}$ & $.27105(.21987)$ & $-.11034(.0857225)$ & $.30947 * *(1314975)$ \\
\hline $\mathrm{DH}$ & $.03902 * * *(.02285)$ & $.02811^{* * *}(.01516)$ & $.00224 * * *(.03714)$ \\
\hline $\mathrm{H}(\mathrm{Ym} \mathrm{m}-\mathrm{Y})$ & $.00129 * *(.00051)$ & $.00090 *(.00028)$ & $.00131 *(.00046)$ \\
\hline Constant & $.00588(.00742)$ & $-.00055(.00190)$ & $.00860 *(.00273)$ \\
\hline \hline
\end{tabular}

Note: The dependent variable is DY. DX denotes the growth rate of variable X. Ymax is represented by the average GDP per capita of the OECD countries. The Standard errors are given in parentheses. $\left({ }^{*}\right),\left({ }^{*}\right)$ and (***) denotes that the estimates is statistically significant at $1 \%, 5 \%$ and $10 \%$ level respectively.

Regression (1) from the Table (4.7), shows the coefficient for the catch-up term is positive however insignificant. But after accounting for the endogeneity of physical capital, regression output (3) generates positive significant coefficient for the technology diffusion term which reinforces the proposition that the developing countries may not be catching up to the USA's technology. Both the innovation term and the accumulation of human capital come out to be positive and significant as well. To sum up, for the developing countries, there is evidence for the importance of human capital for technology innovation and for output production. After relaxing the assumption of USA being the technology leader, the result also supports the significance of human capital for technology diffusion and thus suggesting that the developing countries may not be converging solely to the USA's technology.

\section{Conclusion}

The objective of this paper is to investigate the impact of human capital on economic growth. Human capital as a factor input has been considered to be an important determinant of growth. However using panel estimation technique and quality adjusted updated data, this paper fails to provide positive significant effect on output growth for the accumulation of human capital. For the alternative specification based on the NelsonPhelps approach, empirical evidence generates some support for the importance of the stock of human capital; however the effect is almost negligible. Motivated by Engelbrecht (2003), I test for the hybrid specification which models both the accumulation and the level of human capital simultaneously to investigate whether there is a dual role of human capital in explaining growth. Empirical results show substantial evidence to support the fact that both accumulation and level of human capital are concurrently important for economic growth and the previous insignificant or negligible outputs are likely to be results of model misspecification. In addition, regression estimates also suggest tertiary education is more relevant for technology innovation and diffusion providing evidence in favour of the claim by Aghion and Howitt (1998).

Applying the hybrid specification to different sub-samples I find some noteworthy results. For the OECD countries, there is a palpable evidence for technology diffusion which implies the countries are catchingup to the technology leader. Conversely for the developing countries, the imitation term is insignificant when USA's GDP per capita is represented as the technology gap. Instead a positive relationship is derived when the technology gap is denoted as the overall average GDP per capita of the OECD countries. The results are indicative for the developing countries not catching up to the technology leader. They could be possibly converging to some other country which is considerable evidence for the likelihood of convergence clubs.

In summary, based on this study, the empirical evidence supports the hybrid specification that incorporates both the major approaches of modelling human capital indicated by Aghion and Howitt (1998) for determining economic growth. However it should be kept in mind, the results are only indicative rather than conclusive for explaining economic growth under the hybrid model. Further research should focus on studying the dual role of human capital with the use of better available data and improved specification to support the findings of this paper.

\section{Acknowledgements}

I would like to thank my dissertation supervisor Dr. Mark Roberts for guiding me throughout the entire research. 


\section{References}

Books

[1] Aghion, P. \& Howitt, P. (1998). Endogenous Growth Theory.MIT Press, Cambridge, MA.

[2] Grossman, G.M. \&Helpman, E. (1991). Innovation and Growth in the Global Economy, MIT Press,Cambridge, MA.

[3] Cameron, A.C. \&Trivedi, P. K. (2005). Microeconometrics- Methods and Applications.Cambridge University Press.

[4] Cameron, A.C. \&Trivedi, P.K. (2009). Microeconometrics Using Stata.Stata Press.

Journals

[5] Lucas,R.(1988).On the Mechanics of Economic Development. Journal of Monetary Economics, 22, 2-42.

[6] Nelson, R. \& Phelps, E. (1966). Investments in humans, technological diffusion, and economic growth.American Economic Review, $51,69-75$.

[7] Benhabib, J. \& Spiegel, M. (1994). The role of human capital in economic development: Evidence from aggregate cross-country data. Journal of Monetary Economics, 39, 143-173.

[8] Pritchett, L. (2001). Where has all education gone? World Bank Economic Review, 15, 367-391.

[9] Mankiw, G., Romer, D. \& Weil, D. ( 1992). A contribution to the empirics of economic growth.Quarterly Journal of Economics, 407-437.

[10] Barro, R. (1991). Economic growth in a Cross Section of Countries.Quarterly Journals of Economics, 106(1), 407-443.

[11] Temple, J. (1999). A positive effect of human capital on growth.Economics Letters, 65, 131-134.

[12] Krueger, A.B \&Lindahl, M. (2001). Education for growth: Why and for whom? Journal of Economic Literature, 1101-1136.

[13] Engelbrecht, H.J. (2003). Human Capital and Economic Growth: Cross-Section Evidence for OECD Countries. Economic Record, 79.

[14] Papageorgiou, C. (2003). Distinguishing Between the Effects of Primary and Post-Primary Education on Economic Growth. Review of Developmental Economics, 7(4), 622-635.

[15] Yaffe, R. A. (2002). Robust Regression Analysis: Some Popular Statistical Package Options. Connect, Spring 2002.

[16] Harberger, A.C. (1987).The Macroeconomics of Successful Development: What Are the Lessons? NBER Macroeconomics Annual, 225-258.

[17] Caselli, F., Gerardo, E. \& Fernando, L. (1996). Reopening the convergence Debate: A new Look at Cross-Country Growth Empirics. Journal of Economic Growth, 1(3), 363-390.

[18] Cohen, D. \& Soto, M. (2007). Growth and Human Capital: Good Data, Good Results. Journal of Economic growth, 12(1), 51-76.

[19] Barro, R. \& Lee, J-W. (1993). International Comparison of the Educational Attainment.Journal of Monetary Economics, 32(3), 363-394.

[20] Bernanke, B.S. \&Gurkaynak, R.S.( 2001). Is growth exogenous? Taking Mankiw, Romer and Weil seriously.NBER Macroeconomics Annual, 11-57.

[21] Hanushek, E. \&Kimko, D.(2000). Schooling, labour force quality, and the growth of nations. American Economic Review, 90,11841208.

[22] Liu, Z. (1998). Foreign Direct Investment and Technology Spillovers: Theory and Evidence. Journal of Development Economics, 84, 176-193.

[23] Borensztein, E.,De Gregorio, J. \& Lee, J.-W. (1998). How does foreign investment affect economics growth? Journal of International Economics, 45,115-135.

[24] Engelbrecht, H. J. (2002). Human Capital and international Knowledge spillovers in TFP growth of a sample of developing countries: an exploration of alternative approaches. Applied Economics, 34, 831-841.

Working papers

[25] Schütt, F. (2003).The importance of Human Capital for Economic Growth.Institute for World Economics and International Management, band no: 27.

[26] Barro, R. \& Lee, J-W. (2010). A New Data Set of Educational Attainment in the World.Working Paper 15902, National Bureau of Economic Research.

[27] Tiruneh, M. \&Radvansky, M. (2011). The Contribution of Human Capital to European Economic Growth: An empirical exploration from a panel data. Working Paper in Institute of Economic Research.

[28] Machin, S. \& McNally, S. (2007). Tertiary Education Systems and Labour Markets.Education and Policy Division: OECD.

[29] Ben-David, D. (1994). Convergence clubs and diverging economies. CEPR Discussion Paper Series 922.

Others

[30] World Bank (2011), World Development Indicators. Retrieved July 15, 2012, from World Databank: http://data.worldbank.org/data-catalog/world-development-indicators

[31] Heston, A., Summers, R. \&Aten, B. (2011). Penn World Table Version 7.1.CenterFor International Comparisons of Production, Income and Prices at the University of Pennsylvania. 